\title{
The role of work stress as a moderating variable in the chronic pain and depression association
}

\author{
Sarah E.P. Munce ${ }^{\mathrm{a}, *}$, Iris Weller ${ }^{\mathrm{e}}$, Emma K. Robertson Blackmore ${ }^{\mathrm{b}}$, Margus Heinmaa ${ }^{\mathrm{c}}$, \\ Joel Katz ${ }^{\mathrm{d}}$, Donna E. Stewart ${ }^{\mathrm{a}}$ \\ a'Women's Health Program, University Health Network, University of Toronto, Toronto, Ontario, Canada \\ ${ }^{b}$ Department of Psychiatry, University of Rochester Medical Center, Rochester, NY, USA \\ 'Department of Psychiatry, Hospital for Sick Children, Universitv of Toronto, Toronto, Ontario, Canado \\ dDepartment of Psychology and School of Kinesiology and Health Science, York University, Toronto, Ontario, Canada \\ 'Department of Orthopaedics, Sunnybrook and Women's College Health Sciences Centre, University of Toronto, Toronto, Ontario, Canada
}

\begin{abstract}
Objective: This article aims to examine the role of work stress as a moderating variable in the chronic pain-depression association, as well as sex differences in this link. Methods: The analyses were carried out using the Canadian Community Health Survey Cycle 1.1. Key variables were chronic pain conditions (fibromyalgia, arthritis/rheumatism, back problems, and migraine headaches), work stress, and depression. The total sample comprises 78,593 working individuals. Results: In this working sample, $7.6 \%$ met criteria for major depression, but the prevalence increased to $12 \%$
\end{abstract}

in those also reporting chronic pain. Both depression and comorbid chronic pain and depression were twice as prevalent in women as in men. Having a chronic pain condition and overall work stress emerged as the strongest predictors of depression. Unexpectedly, however, none of the work stress domains moderated the chronic pain and depression association. Conclusion: The impact of work stress should be considered in the etiology and management of major depression.

Keywords: Chronic pain; Depression; Epidemiological; Gender; Work stress

\section{Introduction}

Depression is the leading cause of disability in individuals aged $18-44$ years, and it will be the second leading cause of disease-related disability in people of all ages by 2020 [1]. Adding to the already substantial symptom profile and role impairment associated with depression is the fact that medical illnesses such as chronic pain conditions are a major risk factor for depression, and they often co-occur $[2,3]$. In fact, the prevalence of depression in chronic pain samples has been estimated at 31-100\% [4], significantly

* Corresponding author. Women's Health Program, University Health Network, 200 Elizabeth Street, 7 EN 232A, Toronto, Ontario, Canada M5G 2C4. Tel.: +1 416340 4800x8950; fax: +1 4163404185 .

E-mail address: sarah.munce@uhn.on.ca (S.E.P. Munce). higher than the rate of $5-8 \%$ found in the general population [5]. However, this link is not surprising given the physiological and psychological overlaps between pain and emotion and/or mood [6-8]. Attempts to develop a more comprehensive picture of this complex relationship have involved the study of modifying variables such as disability [9] and, more recently, illness attitudes [10]. Psychosocial stress has also been shown to interact with pain and depression [11-15]. Most studies have indicated that a higher number of stressful life events are associated with increased pain sensitivity and the subsequent higher prevalence of (chronic) pain states [13]. This response can then lead to maladaptive coping strategies, especially in the depressed individual, which can, in turn, lead to more pain. Thus, stress contributes to the development, exacerbation, and maintenance of pain [16]. Work stress, specifically, has 
been associated with an increased number of somatic symptoms such as neck and shoulder pain [17].

Work stress is commonly conceptualized by Karasek's Job Demand-Control (JDC) model of job strain [18]. The "strain" hypothesis states that a "high-strain" job, with high psychological demands and low decision latitude (comprising skill discretion and decision authority), will yield the most detrimental reactions in terms of psychological stress and physical illness. High levels of decision latitude have been shown to be protective of mental health outcomes in both cross-sectional [19-21] and longitudinal [22,23] studies. In one epidemiological study, lack of decision authority, specifically, rather than deficits in skill discretion, was the strongest predictor of depression [20].

This study, using a sample of working individuals who participated in the Canadian Community Health Survey (CCHS) Cycle 1.1, aims to examine the role of Karasek's JDC model as a moderating variable in the chronic paindepression link and explore sex differences in this association. We predicted that a high level of job strain, particularly low job decision latitude, would moderate the chronic pain and depression association and that more women will experience both high levels of work stress and an increased frequency of chronic pain and depression than men. Thus, the present study is distinct from past research in this field in that (a) the data are taken from a large-scale representative sample of working adults, (b) the focus is on work stress, and (c) only clinical levels of depression are included.

\section{Methods}

\section{Description of the CCHS-1.I}

The CCHS-1.1 was carried out by Statistics Canada [24], with the primary objective of providing cross-sectional estimates of health determinants, health status, and health system utilization for 136 health regions in Canada. Data collection took place between September 2000 and November 2001 and produced a response rate of $85 \%$. The target population of the CCHS included individuals aged 12 years or older living in private dwellings in the 10 provinces and three territories. Individuals living in Indian Reserves or Crown lands, institutional residents, full-time members of the Canadian Forces, and residents of certain remote areas were excluded. To provide reliable estimates for the 136 health regions in Canada, we needed a net sample of 134,000 respondents. With few exceptions, every health region had at least 500 respondents [25]. The CCHS-1.1 used multistaged, stratified random sampling procedures, including the Labor Force Survey area frame and the random digit dialing frame [25]. The data were collected by trained Statistics Canada interviewers using the computerassisted personal or telephone interview method. Informed consent was obtained by Statistics Canada.

\section{Main variables of interest}

\section{Chronic pain}

Separate chronic pain conditions were listed in the CCHS-1.1, including self-disclosure of fibromyalgia, arthritis/rheumatism, back problems, and migraine/headaches. The definition of these chronic pain conditions included two criteria: (a) the condition was reported to have been diagnosed by a health care professional and (b) it had lasted at least 6 months. Individuals who responded "yes" to having at least one of these conditions were included in the chronic pain group. The respondents' age at diagnosis was also recorded.

\section{Depression}

The Composite International Diagnostic Interview-Short Form for Major Depression (CIDI-SFMD) of the World Health Organization (WHO) [26] was used to measure a major depressive episode (MDE) in the CCHS-1.1. Subjects were asked about symptoms occurring in the 12 months preceding the interview. The full version of the CIDI was specifically developed by the WHO to measure depression in epidemiological studies and was based on the Diagnostic and Statistical Manual of Mental Disorders, Fourth Edition $(D S M-I V)$ criteria for major depression. The interview schedule was developed and validated by Kessler et al. [27] and has been used in many epidemiological studies of depression in samples ranging in age from 12 to more than 60 years $[5,28]$. The CIDI underwent extensive field testing on individuals aged 15 years and older during the U.S. National Comorbidity Survey $[27,29]$. The diagnostic accuracy of the CIDI depressive module has shown to be good among adolescents [30], the elderly [31], and medically ill populations [32]. The CIDI-SFMD uses a $90 \%$ predictive cut point to represent an MDE. In order to report "caseness" of an $\mathrm{MDE}$, this $90 \%$ cut point is used and corresponds to reporting five of the eight depressive symptoms (depressed mood, loss of interest, fatigue, difficulties in sleeping and concentration, weight gain or loss, feelings of worthlessness, and suicidal ideation) in the same 2-week period over the past 12 months, at least one of which should be depressed mood or loss of interest. This cutoff choice is justified not only by its face validity for the $D S M-I V$ criteria [33] but also because of its high sensitivity $(90 \%)$ and specificity (94\%) when compared with the full version of the CIDI. The overall classification accuracy of the CIDI-SFMD in identifying an MDE is 93\% [34].

\section{Work stress}

Work stress or job strain was measured using a condensed version of Karasek's Job Content Questionnaire (JCQ) [35]. It assesses the constructs of job demands and decision latitude using six subscales: psychological demands and physical exertion (job demands), skill discretion and decision authority (job decision latitude), job insecurity, and social support. There is also a total score for job strain, 
Table 1

A comparison between subjects with a chronic pain condition (CPC) and those without a CPC with respect to demographic characteristics

\begin{tabular}{|c|c|c|c|c|}
\hline Variable & With a CPC & Weighted \% & Without a CPC & Weighted \% \\
\hline \multicolumn{5}{|l|}{ Sex } \\
\hline Male & 10,495 & 25.0 & 28,599 & 75.0 \\
\hline Female & 14,415 & 34.5 & 25,084 & 65.5 \\
\hline Age (mean $\pm S . D)$. & $41.0 \pm 12.7$ & - & $36.7 \pm 12.9$ & - \\
\hline \multicolumn{5}{|l|}{ Marital status } \\
\hline Married/Common law & 15,282 & 66.1 & 29,655 & 59.4 \\
\hline Widowed/Separated/Divorced & 3881 & 11.1 & 6074 & 7.8 \\
\hline Single & 5723 & 22.8 & 17,884 & 32.8 \\
\hline Total household income (mean \pm S.D.) & $65,313.8 \pm 44,273.9$ & - & $68,105.1 \pm 48,390.0$ & - \\
\hline \multicolumn{5}{|l|}{ Education } \\
\hline High school or less & 9797 & 38.4 & 21,921 & 38.4 \\
\hline Postsecondary & 14,891 & 61.6 & 31,291 & 61.6 \\
\hline \multicolumn{5}{|l|}{ Occupation } \\
\hline Management & 2512 & 10.7 & 5299 & 10.4 \\
\hline Professional & 3744 & 15.8 & 7946 & 15.9 \\
\hline Technologist & 1637 & 7.5 & 3963 & 8.8 \\
\hline Administrative/Financial/Clerical & 3263 & 13.9 & 5844 & 11.6 \\
\hline Sales/Service & 6012 & 23.6 & 12,880 & 23.6 \\
\hline Trades/Transport/Equipment operator & 3381 & 13.7 & 7881 & 14.3 \\
\hline Farming/Forestry/Fishing/Mining & 1399 & 3.3 & 3232 & 3.5 \\
\hline Processing/Manufacturing/Utilities & 1046 & 4.5 & 2598 & 5.5 \\
\hline Other & 1739 & 7.0 & 3612 & 6.7 \\
\hline \multicolumn{5}{|l|}{ Race } \\
\hline Caucasian & 22,930 & 89.8 & 47,774 & 84.4 \\
\hline Non-Caucasian & 1808 & 10.2 & 5464 & 15.6 \\
\hline
\end{tabular}

or "all items," which includes all scales. The work stress scores, including all items, skill discretion, decision authority, and psychological demands, were dichotomized as either high or low by using the median score as the cut point, in accordance with previous literature [20]. Selfperceived work stress was also examined using responses on a five-point continuum ranging from not at all stressful to extremely stressful.

\section{Statistical analysis}

In this analysis, estimates of prevalence were calculated using the sampling weights provided by Statistics Canada; in addition, its guidelines for calculating confidence intervals were followed [24]. Reported percentages, therefore, are weighted while reported sample sizes are the actual number of observed subjects. Associations between categorical data were analyzed using the nonparametric chi-square test.

The bootstrap, a widely used method of analyzing the sampling variability of complex statistical models, was used to calculate $95 \%$ confidence intervals around the adjusted estimator [36]. Logistic regression was conducted to estimate the likelihood of having major depression based on the presence of having at least one of the chronic pain conditions. The covariates of age, marital status, and socioeconomic status were also examined. The sampling design and weights were accounted for in the analysis by using the bootstrap statistics (500 weights). In order to determine the role of various aspects of work stress in the chronic pain and depression association, we examined interaction terms. To assess the fit of the models, we compared deviances from fitting the model with and without the covariates. The differences in the deviances were assumed to follow a chi-square distribution. The statistical software SPSS (Version 12.0, SPSS, 2003) was used to perform the analyses.

\section{Results}

Demographics and pain and work stress characteristics

\section{Chronic pain}

The total sample of the CCHS (Cycle 1.1) was 135,535 individuals. We included only individuals who had been working in the past 12 months, yielding a study sample of 78,593 individuals, $52 \%$ of whom were male.

Thirty percent of this working sample had a chronic pain condition, with $56 \%$ representing female respondents. A significant Sex $\times$ Chronic Pain Condition Status association was observed $\left[\chi^{2}(1)=177,492.97, P<.00001\right]$ (Table 1). Of the total number of individuals with chronic pain, $12 \%$ were depressed. Of the total number of depressed individuals, $47 \%$ reported having at least one chronic pain condition. A significant Chronic Pain Condition Status $\times$ Depression Status association was also detected $\left[\chi^{2}(1)=202,644.73\right.$, $P<.00001]$. Lastly, there was a significant Chronic Pain Condition Status $\times$ Work Stress Score association $\left[\chi^{2}(1)=\right.$ $55,869.81, P<.00001]$ (Table 2), with $61 \%$ of individuals with a chronic pain condition versus $55 \%$ of individuals without a chronic pain condition reporting higher levels of work stress. Demographic profiles and pain and work stress 
Table 2

A comparison between subjects with a chronic pain condition (CPC) and those without a CPC with respect to pain and work characteristics

\begin{tabular}{|c|c|c|c|c|}
\hline Variable & $\begin{array}{l}\text { With a } \\
\text { CPC }\end{array}$ & $\begin{array}{l}\text { Weighted } \\
\%\end{array}$ & $\begin{array}{l}\text { Without a } \\
\text { CPC }\end{array}$ & $\begin{array}{l}\text { Weighted } \\
\%\end{array}$ \\
\hline \multicolumn{5}{|c|}{ Usually free of pain and discomfort } \\
\hline Yes & 17,001 & 69.2 & 50,482 & 94.4 \\
\hline No & 7894 & 30.8 & 3151 & 5.6 \\
\hline \multicolumn{5}{|c|}{ Pain and discomfort-usual intensity } \\
\hline Mild & 2542 & 32.6 & 1488 & 47.5 \\
\hline Moderate & 4436 & 55.0 & 1419 & 44.6 \\
\hline Severe & 904 & 12.4 & 239 & 8.0 \\
\hline \multicolumn{5}{|c|}{ Pain and discomfort-number of activities prevented } \\
\hline None & 2115 & 26.0 & 1495 & 49.0 \\
\hline A few & 2675 & 35.5 & 980 & 31.7 \\
\hline Some & 2035 & 26.1 & 451 & 13.4 \\
\hline Most & 1057 & 12.4 & 218 & 5.9 \\
\hline \multicolumn{5}{|c|}{ Self-perceived work stress } \\
\hline Not at all & 2261 & 8.6 & 6478 & 11.5 \\
\hline Not very & 3990 & 15.7 & 10,556 & 19.1 \\
\hline A bit & 9431 & 37.3 & 21,203 & 39.5 \\
\hline Quite a bit & 6763 & 28.7 & 12,142 & 24.5 \\
\hline Extremely & 2149 & 9.7 & 2716 & 5.5 \\
\hline \multicolumn{5}{|c|}{ Work stress (meantS.D.) } \\
\hline All items & $19.9 \pm 5.2$ & - & $19.1 \pm 5.0$ & - \\
\hline Skill discretion & $5.0 \pm 2.3$ & - & $4.9 \pm 2.3$ & - \\
\hline Decision authority & $2.7 \pm 1.8$ & - & $2.7 \pm 1.8$ & - \\
\hline Psychological demands & $4.6 \pm 1.8$ & - & $4.3 \pm 1.8$ & - \\
\hline
\end{tabular}

characteristics were compared with respect to chronic pain condition status using chi-square and Student's $t$ tests. Significant between-groups differences were observed on all variables. The results are reported in Tables 1 and 2 .

\section{Depression}

The rate of major depression as determined by the CIDISFMD was estimated at $7.6 \%$ in the working population ( $5.2 \%$ in males, $10.2 \%$ in females), while the prevalence of depression in the unemployed population was $8.3 \%(6.4 \%$ in males, $9.3 \%$ in females). A significant Sex $\times$ Depression Status association was detected $\left[\chi^{2}(1)=145,046.63, P<\right.$ $.00001]$ (Table 3). Demographic profiles and pain and work stress characteristics were compared with respect to depression status using chi-square and Student's $t$ tests. Significant between-groups differences were observed on all variables. The results are reported in Tables 3 and 4 .

\section{Work stress}

Fifty-seven percent of the respondents had a higher all items work stress score (i.e., above the median score), with an equal proportion of men and women. As noted above, there was a significant Chronic Pain Condition Status $\times$ Work Stress Score association reported. Demographic profiles and pain and work stress characteristics were compared with respect to work stress score using chi-square and Student's $t$ tests. Significant between-groups differences were observed on all variables. The results are reported in Tables 5 and 6.

\section{Main model analysis: logistic regression}

After controlling for age, marital status, and socioeconomic status, the independent variables of work stress (all items, skill discretion, decision authority, and psycho-

Table 3

A comparison between subjects with depression (DEP) and those without DEP with respect to demographic characteristics

\begin{tabular}{|c|c|c|c|c|}
\hline Variable & With DEP & Weighted \% & Without DEP & Weighted \% \\
\hline \multicolumn{5}{|l|}{ Sex } \\
\hline Male & 2135 & 5.3 & 36,115 & 94.7 \\
\hline Female & 4300 & 10.3 & 34,331 & 89.7 \\
\hline Age (mean \pm S.D.) & $35.2 \pm 12.0$ & - & $38.2 \pm 13.0$ & - \\
\hline \multicolumn{5}{|l|}{ Marital status } \\
\hline Married/Common law & 2694 & 46.6 & 41,338 & 62.8 \\
\hline Widowed/Separated/Divorced & 1358 & 14.5 & 8323 & 8.2 \\
\hline Single & 2379 & 38.9 & 20,706 & 29.1 \\
\hline Total household income (mean \pm S.D.) & $58,225.5 \pm 44,494.8$ & - & $68,068.2 \pm 47,420.6$ & - \\
\hline \multicolumn{5}{|l|}{ Education } \\
\hline High school or less & 1585 & 22.1 & 15,764 & 19.1 \\
\hline Postsecondary & 4707 & 77.9 & 53,259 & 80.9 \\
\hline \multicolumn{5}{|l|}{ Occupation } \\
\hline Management & 499 & 8.0 & 7169 & 10.6 \\
\hline Professional & 867 & 14.6 & 10,622 & 16.0 \\
\hline Technologist & 341 & 5.8 & 5179 & 8.6 \\
\hline Administrative/Financial/Clerical & 899 & 14.5 & 8088 & 12.1 \\
\hline Sales/Service & 2009 & 30.4 & 16,570 & 23.0 \\
\hline Trades/Transport/Equipment operator & 780 & 11.7 & 10,312 & 14.3 \\
\hline Farming/Forestry/Fishing/Mining & 246 & 2.2 & 4319 & 3.5 \\
\hline Processing/Manufacturing/Utilities & 267 & 4.3 & 3297 & 5.2 \\
\hline Other & 517 & 8.4 & 4739 & 6.6 \\
\hline \multicolumn{5}{|l|}{ Race } \\
\hline Caucasian & 5844 & 88.5 & 63,806 & 85.8 \\
\hline Non-Caucasian & 573 & 11.5 & 6480 & 14.2 \\
\hline
\end{tabular}


Table 4

A comparison between subjects with depression (DEP) and those without DEP with respect to various pain and work stress characteristics

\begin{tabular}{|c|c|c|c|c|}
\hline Variable & $\begin{array}{l}\text { With } \\
\text { DEP }\end{array}$ & $\begin{array}{l}\text { Weighted } \\
\%\end{array}$ & $\begin{array}{l}\text { Without } \\
\text { DEP }\end{array}$ & $\begin{array}{l}\text { Weighted } \\
\%\end{array}$ \\
\hline \multicolumn{5}{|c|}{ Usually free of pain and discomfort } \\
\hline. Yes & 4572 & 71.2 & 61,541 & 88.3 \\
\hline No & 1862 & 28.8 & 8879 & 11.7 \\
\hline \multicolumn{5}{|c|}{ Pain and discomfort-usual intensity } \\
\hline Mild & 531 & 28.5 & 3393 & 38.9 \\
\hline Moderate & 1071 & 58.2 & 4637 & 50.6 \\
\hline Severe & 259 & 13.2 & 837 & 10.5 \\
\hline \multicolumn{5}{|c|}{ Pain and discomfort-number of activities prevented } \\
\hline None & 414 & 22.2 & 3100 & 35.2 \\
\hline A few & 612 & 35.3 & 2959 & 34.2 \\
\hline Some & 507 & 25.7 & 1907 & 21.5 \\
\hline Most & 326 & 16.7 & 900 & 9.1 \\
\hline \multicolumn{5}{|l|}{ Self-perceived work stress } \\
\hline Not at all & 523 & 7.7 & 8017 & 10.8 \\
\hline Not very & 881 & 13.2 & 13,390 & 18.5 \\
\hline A bit & 2147 & 32.4 & 27,841 & 39.4 \\
\hline Quite a bit & 1942 & 31.8 & 16,557 & 25.3 \\
\hline Extremely & 860 & 14.8 & 3864 & 6.0 \\
\hline \multicolumn{5}{|l|}{ Work stress (mean \pm S.D.) } \\
\hline All items & $21.5 \pm 5.5$ & - & $19.1 \pm 5.0$ & - \\
\hline Skill discretion & $5.2 \pm 2.3$ & - & $4.9 \pm 2.3$ & - \\
\hline Decision authority & $3.2 \pm 2.0$ & - & $2.7 \pm 1.8$ & - \\
\hline Psychological demands & $4.9 \pm 1.8$ & - & $4.4 \pm 1.8$ & - \\
\hline
\end{tabular}

logical demands) were all found to significantly predict major depression. Specifically, individuals with high overall work stress were 1.8 times more likely to be depressed than those individuals with low overall work stress. The low skill discretion group was 1.2 times more likely to be depressed than those individuals with high skill discretion, and the low decision authority group and high psychological demands group were both 1.5 times more likely to be depressed than those individuals in the high decision authority and low psychological demands groups.

Unexpectedly, none of the domains of work stress moderated the chronic pain and depression association. However, the Chronic Pain $\times$ Skill Discretion interaction term almost reached significance $(P=.07)$. That is, there was a trend for the presence of a chronic pain condition to have more of an impact for those individuals in the low skill discretion group (than those in the high skill discretion group) in terms of raising the risk of depression [odds ratio $(\mathrm{OR})=1.2$ ].

For both males and females, no aspect of work stress moderated the chronic pain and depression association. All aspects of work stress as independent predictors for major depression were slightly but not significantly more pronounced in men.

Overall, the presence of a chronic pain condition emerged as the strongest predictor of depression among all variables and interactions examined. Working individuals with a chronic pain condition were about 2.5 times more likely to be depressed than employed individuals without a chronic pain condition.

\section{Discussion}

There were two important findings of this study regarding the role of work stress in the chronic pain and

Table 5

A comparison between subjects with higher work stress (WS) scores and those with lower WS scores with respect to demographic characteristics

\begin{tabular}{|c|c|c|c|c|}
\hline Variable & Higher WS & Weighted \% & Lower WS & Weighted $\%$ \\
\hline \multicolumn{5}{|l|}{ Sex } \\
\hline Male & 13,688 & 50.0 & 16,155 & 54.7 \\
\hline Female & 15,373 & 50.0 & 14,396 & 45.3 \\
\hline Age (mean $\pm S . D)$. & $36.6 \pm 13.0$ & - & $39.1 \pm 12.7$ & - \\
\hline \multicolumn{5}{|l|}{ Marital status } \\
\hline Married/Common law & 15,546 & 56.8 & 18,728 & 65.7 \\
\hline Widowed/Separated/Divorced & 3728 & 9.3 & 3751 & 8.2 \\
\hline Single & 9757 & 34.1 & 8038 & 26.1 \\
\hline Total household income (mean \pm S.D.) & $60,129.1 \pm 41,874.1$ & - & $75,021.4 \pm 52,051.0$ & - \\
\hline \multicolumn{5}{|l|}{ Education } \\
\hline High school or less & 7862 & 24.2 & 5751 & 15.1 \\
\hline Postsecondary & 20,570 & 75.8 & 24,231 & 84.9 \\
\hline \multicolumn{5}{|l|}{ Occupation } \\
\hline Management & 1984 & 7.0 & 3947 & 13.7 \\
\hline Professional & 2892 & 9.7 & 6037 & 21.8 \\
\hline Technologist & 1692 & 6.5 & 2763 & 10.8 \\
\hline Administrative/Financial/Clerical & 2768 & 10.4 & 4050 & 13.9 \\
\hline Sales/Service & 8619 & 29.6 & 5411 & 17.2 \\
\hline Trades/Transport/Equipment operator & 4810 & 17.5 & 3899 & 11.3 \\
\hline Farming/Forestry/Fishing/Mining & 1766 & 3.4 & 1641 & 2.7 \\
\hline Processing/Manufacturing/Utilities & 2127 & 8.2 & 986 & 3.3 \\
\hline Other & 2207 & 7.7 & 1629 & 5.1 \\
\hline \multicolumn{5}{|l|}{ Race } \\
\hline Caucasian & 26,556 & 85.9 & 28,047 & 87.0 \\
\hline Non-Caucasian & 2329 & 14.1 & 2307 & 13.0 \\
\hline
\end{tabular}


Table 6

A comparison between subjects with higher work stress (WS) scores and those with lower WS scores with respect to various pain and WS characteristics

\begin{tabular}{|c|c|c|c|c|}
\hline Variable & Higher WS & Weighted \% & Lower WS & Weighted \% \\
\hline \multicolumn{5}{|c|}{ Usually free of pain and discomfort } \\
\hline Yes & 23,888 & 83.2 & 27,383 & 90.6 \\
\hline No & 5161 & 16.8 & 3163 & 9.4 \\
\hline \multicolumn{5}{|c|}{ Pain and discomfort-usual intensity } \\
\hline Mild & 1746 & 34.1 & 1260 & 40.9 \\
\hline Moderate & 2803 & 53.7 & 1617 & 49.3 \\
\hline Severe & 609 & 12.2 & 284 & 9.8 \\
\hline \multicolumn{5}{|c|}{ Pain and discomfort - number of activities prevented } \\
\hline None & 1663 & 32.1 & 1123 & 35.7 \\
\hline A few & 1719 & 34.1 & 1042 & 34.9 \\
\hline Some & 1142 & 22.2 & 685 & 21.3 \\
\hline Most & 631 & 11.6 & 308 & 8.1 \\
\hline \multicolumn{5}{|c|}{ Self-perceived WS } \\
\hline Not at all & 2799 & 9.5 & 3750 & 11.5 \\
\hline Not very & 4664 & 15.7 & 6260 & 19.3 \\
\hline A bit & 10,962 & 37.2 & 12,422 & 39.7 \\
\hline Quite a bit & 7990 & 27.9 & 6893 & 25.0 \\
\hline Extremely & 2625 & 9.7 & 1207 & 4.6 \\
\hline
\end{tabular}

depression association. First, this study confirmed in a large, representative, working sample the significant association between chronic pain and depression. Second, work stress, especially low decision authority and high psychological demands, conferred a significant, independent risk for depression.

In this sample from the CCHS-1.1, the prevalence rate of depression in workers with chronic pain was $12 \%$, a lower rate than the $18 \%$ previously reported in a large U.S. household survey [37]. It is quite likely that this lower rate reflects the characteristics of a healthier, working population. It should also be noted that the rate of depression in the chronic pain sample was greater than the rate of depression in the general population ( $8 \%$ ). This finding is consistent with previous literature, which has reported a prevalence rate of 5-8\% for depression in the general U.S. population [5]. The prevalence of depression in individuals without chronic pain was $6 \%$, which was half the prevalence rate of individuals with chronic pain.

The impact of each domain of work stress as an independent predictor of major depression was significant. High overall work stress emerged as the strongest predictor, conferring almost double the risk of depression, roughly equivalent to the risk of female sex. This finding was consistent with previous literature $[20,38]$. However, this study is unique in that it was able to confirm this association in such a large epidemiological Canadian sample. It is especially interesting to note that, in accordance with previous literature, low decision authority $(\mathrm{OR}=1.5)$ was slightly more predictive of major depression than low skill discretion (OR=1.2) [20]. Tsutsumi et al. [38] found that "low decision latitude" had an OR of 4.7 in predicting major depression. While this study separated the decision latitude scale into skill discretion and decision authority, it would have been interesting to compare the results with Tsutsumi's work, as it seems to suggest that the combination of low skill discretion and decision authority confers the greatest risk of depression. In contrast to earlier literature, which has demonstrated that psychological demands, specifically, are more related to anxiety than depressive symptoms $[21,39]$, this study found that high psychological demands (as well low decision authority) were the strongest predictor of major depression. More recent work [28] has found that high psychological demands predicted major depression more strongly in men than women (gender analyses are further discussed below).

The findings of the main model analyses were more surprising. Despite the substantial main effects of work stress on major depression and despite previous literature that has demonstrated a relationship between pain, stress, and depressive symptoms [15], this study did not demonstrate a moderating role for various aspects of work stress on the chronic pain and depression link. There are several possible explanations for our results. First, this study had a healthy sample bias because it was limited to a working population. Therefore, individuals who continue to work despite their chronic pain are likely to have different characteristics from their nonworking counterparts, and it is possible that this difference accounts for the absence of an effect on the risk of major depression. It is unknown whether this difference can be attributed to less severe chronic pain or a superior set of coping skills (possibly produced by the chronic pain condition itself or the work environment) or to a combination of these factors. It is also possible that work, with its associated activity level and social supports, serves as a "distraction" for individuals with chronic pain; hence, their risk of depression is not further increased. Future research in this area is needed to address what specific role work stress plays in chronic pain.

Noteworthy, however, was a trend indicating that the presence of chronic pain had more of an impact for those individuals with low skill discretion (rather than high skill discretion) in terms of raising the risk of depression. Although this interaction term was not significant, the trend corresponded to the original hypothesis indicating that low decision latitude (i.e., which comprises skill discretion and decision authority), in particular, would moderate the chronic pain and depression association. This trend highlights the role of affective reactions and experiences and expectations in the pain state as well as its chronicity. Thus, if individuals with chronic pain have low skill discretion (little variety) at work, then they may have few sources of stimulation to keep them distracted from their pain. This lack of variety, in turn, may be associated with an increased risk of depression or, at the very least, distress. Future studies should focus on continuous indices of severity for chronic pain and depression (which were unavailable in this database) to get a better picture of the role of skill discretion in this association. It is also important to consider the possibility that responses to the low skill discretion (such as feelings of helplessness, catastrophizing, and other coping 
difficulties) are associated with further psychological distress (depression).

With respect to gender analyses, the observations were in accordance with the existing trends in the literature, indicating a higher prevalence of chronic pain conditions among females $(56 \%)$. Although a review of studies that examined gender differences in comorbid chronic pain and depression did not reveal definitive conclusions [40], this study provided support for a higher prevalence of comorbid chronic pain and depression among females (68\%). The fact that the effects of work stress on the risk of depression were slightly more pronounced in males than females may represent stereotypical pressures and expectations on men, such as their being the income earner in their household.

A limitation of the present study and cross-sectional analysis in general is the inability to establish cause and effect. In the present study, there is no way to determine whether major depression is the result of chronic pain or a causative factor. Although current research seems to indicate that, most often, depression is a logical consequence of chronic pain [41.42], this remains an unresolved question. There is similar ambiguity with respect to the directionality of the association between work stress and depression (i.e., stress at work could lead to depression but, at the same time, negative affectivity could determine the perception of various situations at work). Other limitations are related to the restrictions of the database, such as depression, work stress, and chronic pain variables. For example, MDD was only available as a dichotomous variable. Although this parameter allowed a stringent outcome variable, the use of depression as a continuous variable or even the use of subthreshold levels would have provided more information about the interassociation between work stress, chronic pain, and depression. Further, the condensed version of Karasek's JCQ may not have accurately captured the various job strain domains. The determination of chronic pain was also limited in the CCHS1.1. Information on diagnosis and duration was based on selfdisclosure, although the respondents had to have their condition diagnosed by a health care professional (no attempts were made to corroborate respondents' reports of health status using other sources of information) [25]. Further, our definition of chronic pain included a heterogeneous group of conditions with varying severity, etiology, and chronicity/ periodity of pain. Thus, the grouping of these conditions may have masked a specific association between back pain, work stress, and depression. The examination of specific chronic pain conditions may be an area of future research. However, as Currie and Wang [43] noted in their study on chronic back pain and depression using the CCHS-1.1 database, these limitations are typical of epidemiological surveys that focus on general health rather than specific disorders.

Another key limitation of such an epidemiological survey is that because the sample is so large, even small differences can emerge as statistically significant (e.g., as found with the mean work stress scores in comparison with chronic pain and depression status). Development of measures with appropriate norms and clinical cut points would aid in the interpretation of any detected differences. Finally, because this sample was limited to a working population, there is an inherent selection bias. As discussed above, this sample represents a relatively healthy sample and it undoubtedly eliminated the individuals whose chronic pain conditions were so disabling that they were unable to continue working the very people who are at a high of risk of major depression.

In their report on chronic pain based on the CCHS-1.1 database, Meana et al. [44] identified a lack of information on chronic pain and work life, especially for women. The present study attempted to address this gap in a large population sample by examining how work stress affects the chronic pain depression association, as well as sex differences in this association. The presence of work stress, especially low decision authority and high psychological demands, should be addressed as a possible contributor to depression and, where appropriate, as a psychosocial component of treatment. Based on the findings of this study, the impact of work stress on mental health (i.e., depression) needs special attention from health care professionals, employers, work policies, and codes of conduct.

\section{Acknowledgments}

The research and data analyses were carried out at Statistics Canada. However, the opinions and views do not represent those of Statistics Canada.

\section{References}

[1] Murray C, Lopez A. The global burden of disease: a comprehensive assessment of mortality and disability from diseases, injuries, and risk factors in 1990 and projected to 2020. Boston: Harvard University Press, 1996.

[2] Beaudet M. Depression. Health Rep 1996;7:11-24.

[3] Patten S. Long-term medical conditions and major depression in the Canadian population. Can J Psychiatry 1999;44:151-7.

[4] Romano J, Turner J. Chronic pain and depression: does the evidence support a relationship? Psychol Bull 1985;97:18-34.

[5] Kessler R, Berglund P, Demler O, Jin R, Koretz D, Merikangas K, Rush A, Walters $E$, Wang $P$. The epidemiology of major depressive disorder: results from the National Comorbidity Survey Replication (NCS-R). J Am Med Assoc 2003;289:3095-105.

[6] Melzack R. Pain: past, present, and future. Can J Exp Psychol 1993; 47:615-29.

[7] Melzack R. From the gate to the neuromatrix. Pain 1999;(Suppl 6): S121-6.

[8] Richelson E. Biological basis of depression and therapeutic relevance. J Clin Psychiatry 1991;52(Suppl):4-10.

[9] Newman S, Fitzpatrick R, Lamb R, Shipley M. The origins of depressed mood in rheumatoid arthritis. J Rheumatol 1989;16:740-4.

[10] Dickens C, Jayson M, Sutton C, Creed F. The relationship between pain and depression in a trial using paroxetine in sufferers of chronic low back pain. Psychosomatics 2000;41:490-9.

[11] Geertzen J, de Bruijn-Kofman A, de Bruijn H, van de Wiel H, Dijkstra P. Stressful life events and psychosocial dysfunction in complex regional pain syndrome type I. Clin J Pain 1998;14:143-7. 
[12] Klapow J, Slater M, Patterson T, Atkinson J, Weickgenant A, Grant I, Garfin SR. Psychosocial factors discriminate multidimensional clinical groups of chronic low back pain patients. Pain 1995;62: $349-55$.

[13] Labbé E, Murphy L, O'Brien C. Psychosocial factors and prediction of headaches in college adults. Headache 1997;37:1-5.

[14] Niemi S, Levoska S, Rekola K, Keinänen-Kiukaanniemi S. Neck and shoulder symptoms of high school students and associated-psychosocial factors. J Adolesc Health 1997;20:238-42.

[15] Zautra A, Smith B. Depression and reactivity to stress in older women with rheumatoid arthritis and osteoarthritis. Psychosom Med 2001; 63:687-96.

[16] Shipton E. Pain; acute and chronic. New York: Oxford University Press, 1999.

[17] Lundberg U, Dohns I, Melin B, Sandsjö L, Palmerud G, Kadefors R, Ekstrom M, Parr D. Psychophysiological stress responses, muscle tension, and neck and shoulder pain among supermarket cashiers. J Occup Health Psychol 1999;4:245-55.

[18] Karasek R. Job demands, job decision latitude, and mental strain: implications for job redesign. Adm Sci Q 1979;24:285-308.

[19] Hesketh B, Shouksmith G. Job and non-job activities, job satisfaction and mental health among veterinarians. J Occup Behav 1986; 7:325-39.

[20] Mausner-Dorsch H, Eaton W. Psychosocial work environment and depression: epidemiologic assessment of the demand-control model Am J Public Health 2000;90:1765-70.

[21] Warr P. The measurement of well-being and other aspects of mental health. J Occup Psychol 1990;63:193-210.

[22] Niedhammer I, Goldberg M, Leclerc A, Bugel I, David S. Psychological factors at work and subsequent depressive symptoms in the Gazel cohort. Scand J Work Environ Health 1998;24:197-205.

[23] Stansfeld S, Fuhrer R, Shipley M, Marmot M. Work characteristics predict psychiatric disorder: prospective results from the Whitehall II Study. Occup Environ Med 1999;56:302-7.

[24] Statistics Canada. Canadian Community Health Survey Cycle 1.1. 2001. Available www.statcan.ca/english/concepts/health/cchsinfo.html.

[25] Béland Y. Canadian community health survey-methodological overview. Health Rep 2002;13:9-14.

[26] World Health Organization. Composite international diagnostic interview (CIDI), version 10. Geneva: World Health Organization; 1990.

[27] Kessler R, McGonagle K, Nelson C, Hughes M, Swartz M, Blazer D. Sex and depression in the National Comorbidity Study II: cohort effects. J Affect Disord 1994;30:15-26.

[28] Wang J, Patten S. Alcohol consumption and major depression: findings from a follow-up study. Can J Psychiatry 2001;46:632-8.
[29] Kessler R, Walters E. Epidemiology of DSM-III-R major depression and minor depression among adolescents and young adults in the National Comorbidity Survey. Depress Anxiety 1998;7:3-14.

[30] Patton G, Coffey C, Posterino M, Carlin J, Wolfe R, Bowes G. A computerised screening instrument for adolescent depression: population-based validation and application to a two-phase case-control study. Soc Psychiatry Psychiatr Epidemiol 1999;34:166-72.

[31] Turvey C, Carney C, Amdt S, Wallace R, Herzog R. Conjugal loss and syndromal depression in a sample of elders aged 70 years or older. Am J Psychiatry 1999;156:1596-601.

[32] Booth B, Kirchner J, Hamilton G, Harrell R, Smith G. Diagnosing depression in the medically ill: validity of a lay-administered structured diagnostic interview. J Psychiatr Res 1998;32:353-60.

[33] American Psychiatric Association. Diagnostic and statistical manual of mental disorders. Washington (DC): American Psychiatric Association, 1994.

[34] Kessler R, Andrews G, Mroczek D, Ustun B, Wittchen H. The World Health Organization Composite International Diagnostic Interview Short-Form (CIDI-SF). Int J Methods Psychiatr Res 1998;7:171-85.

[35] Karasek R. Job content instrument: questionnaire and user's guide Los Angeles: University of Southern California, 1985.

[36] Last J. A dictionary of epidemiology. New York: Oxford University Press, 1995.

[37] Magni G, Caldieron C, Rigatti-Luchini S, Merskey H. Chronic musculoskeletal pain and depressive symptoms in the general population. An analysis of the 1st National Health and Nutrition Examination Survey data. Pain 1990;43:299-307.

[38] Tsutsumi A, Kayaba K, Theorell T, Siegrist J. Association between job stress and depression among Japanese employees threatened by job loss in a comparison between two complementary job-stress models. Scand J Work Environ Health 2001;27:146-53.

[39] Broadbent $\mathrm{D}$. The clinical impact of job design. Br J Clin Psychol $1985 ; 24: 33-44$

[40] Uhruh A. Gender variations in clinical pain experience. Pain 1996; 65:123-67.

[41] Dersh J, Polatin P, Gatchel R. Chronic pain and psychopathology: research findings and theoretical considerations. Psychosom Med 2002:64:773-86.

[42] Fishbain D, Cutler R, Rosomoff H, Rosomoff R. Chronic painassociated depression: antecedent or consequence of chronic pain? A review. Clin J Pain 1997;13:116-37.

[43] Currie S, Wang J. Chronic back pain and major depression in the general Canadian population. Pain 2004;107:54-60.

[44] Meana M, Cho R, DesMeules M. Chronic pain: the extra burden on Canadian women. BMC Women's Health 2004;4(Suppl 1):S17. 